\title{
Two new species (Diptera: Fanniidae) collected in the Imperial Palace, Tokyo, Japan
}

\author{
Kazumi NiSHIDA \\ Kobe Institute of Health, 4-6, Minatojima-nakamachi, Chuo-ku, Kobe, 650-0046 Japan
}

(Received: 28 January 2002; Accepted: 8 April 2002)

\begin{abstract}
Key words: new species, Fanniidae, the carbonaria group, woodland species, the Imperial Palace
\end{abstract}

\begin{abstract}
Two new species of the Fanniidae (Diptera), Fannia imperatoria sp. nov. and $F$. urbana sp. nov., are described. They were found in the additional collection after the comprehensive investigation on the fauna and flora of the Imperial Palace, Tokyo, Japan, from 1996 to 1999. One specimen of $F$. urbana was collected in the campus of Chiba University. Both species are inhabitants of the forest and woods in the Kanto Plain.
\end{abstract}

\section{INTRODUCTION}

The fauna and flora of the Imperial Palace, Tokyo, had been investigated comprehensively from 1996 to 1999 by the National Science Museum, Tokyo. Seven species belonging to the genus Fannia of family Fanniidae, Fannia canicularis (Linnaeus), F. edentula Nishida, $F$. fulgida Nishida, $F$. japonica japonica Nishida, $F$. prisca Stein, $F$. shinahamae Chillcott and $F$. vernalis Nishida, were recorded as the results of this project. However Fannia scalaris (Fabricius), which is a synanthropic species, has not been collected. For the fauna of fanniids, the Imperial Palace resembles the woods and forest of hilly zone of the Kanto Plain (Nishida, 2000).

The additional investigation is continuing after this project, and two new species of the genus Fannia were added in the collection. Both species belong to the carbonaria sub-group of the carbonaria group, and occur in spring.

Many endemic species in Japan such as $F$. edentula, $F$. fulgida, $F$. j. japonica, $F$. shinahamae and $F$. vernalis inhabit in the broad-leaved evergreen forest. While $F$. j. japonica and $F$. vernalis live not only in hilly zone but also in montane zone. $F . j$.japonica, that ranges from the Japanese Islands to Kamchatka Penn., appears both in early spring and in autumn at low land, moreover in mid summer at high mountains. $F$. vernalis appears in early spring at low land, and in early summer at high mountains.

On the other hand, most Japanese fanniids that inhabit the sub-alpine zone range throughout the Holarctic or Palaearctic region. 
Two new species described in this paper are probably endemic in Japan, because their habits resemble these known endemic species in Japan.

It is notable that nine species are collected in the woods of the Imperial Palace, because it is surrounded by urban area, and very far from the woods or forests in Musasino plateau. It is assumed that the woodland fanniids are impossible to fly between the both areas.

It is possible that the fanniids in the Imperial Palace may have moved from the suburbs in the past years, or they are aboriginal in the area, although the ecological environment inside and around the Imperial Palace in the past is hardly known.

At present time, many woodland fanniids are preserved well in the environment of the Imperial Palace, although it localizes in center of the megalopolis.

\section{DESCRIPTIONS}

Fannia imperatoria sp. nov.

Japanese name: Kinri-hime-iebae

(Figs. 1-3)

Male. Head. Eyes with short but distinct hairs very sparsely. A very long occipital seta and 1-2 short setae present alternately. Upper postoccipital setae in a complete row. Frons weakly arched, narrower than width of ocellar triangle. Frontal setae 10-12, with several interstitials. Ground color of parafacialia, parafrontalia and frontal vitta black. Parafrontalia silvery pollinose, but brownish gray pollinose near ocellar triangle; narrower on upper half. Parafacialia bare, silvery pollinose; broad, as wide as flagellomere at lunula. Frontal vitta brown pollinose; very narrow, but distinct throughout. Antenna black; grayish-brown subpubescent; flagellomere twice as long as wide. Arista black including basal segment, subpubescent, twice as long as flagellomere. Palpi black, filiform, compressed laterally. (Proboscis of the specimen was broken heavily).

Thorax. Ground color black. Scutum subshining, brownish gray pollinose very thinly. Not vittate. Prst acr biserial; post acr triserial, but becoming quadriserial near scutellum. One strong pra present, 2/3 times as long as anterior $n p l$ seta. Proepisternal depression bare; with 2 setae on ridge beneath. Proepimeron with a strong seta surrounded by $9-11$ setulae. Scutellum black, brownish gray pollinose thinly; with a pair of strong laterals and apicals; with numerous long discal setulae placed around margin and before tip.

Wings. Slightly smoky, but yellowish basally. Veins brown, but becoming yellowish basad. Squamae pale yellow, with pale yellow margins; lower one well developed, apparently larger than upper one. Halteres with both stalk and knob orange.

Legs. Black, including knees. Fore femur with a row of strong $p d$ setae; with pluriserial rows of numerous long $p$ setae; with a row of strong $p v$ setae. Fore tibia without $p$ setae, and with no $a d$ at apical quarter. Mid femur with a row of 11-13 strong av setae on basal 


\section{Vol.53 Suppl.2, 2002}

two-thirds, the setae as long as femoral depth but becoming shorter apicad, merging into an irregular row of 10-12 dense short setae in apical third, and with a few short preapical setulae; $a$ surface with a row of short setae, but 4 preapical setae strong and curved backward; $p v$ surface with biserial rows of many close-set setae on basal three quarters, shorter apicad, the setae of an inner row weaker, followed by biserial rows of close-set short setae, and with some fine short setae preapically; with a row of long fine $p$ setae, subequal to femoral depth, and 5-6 preapical setae stronger. Mid tibia thickened on apical half, twice as deep as basal diameter; with a $v$ mat of short uniform fine setulae on apical half, the setulae $2 / 3$ times as long as tibial depth, and with short sparse semi-decumbent $v$ setulae on basal half; with 2 ad and $2 p d$ setae. Mid basal tarsomere without a basal $v$ crest. Hind coxa without any setae on $p$
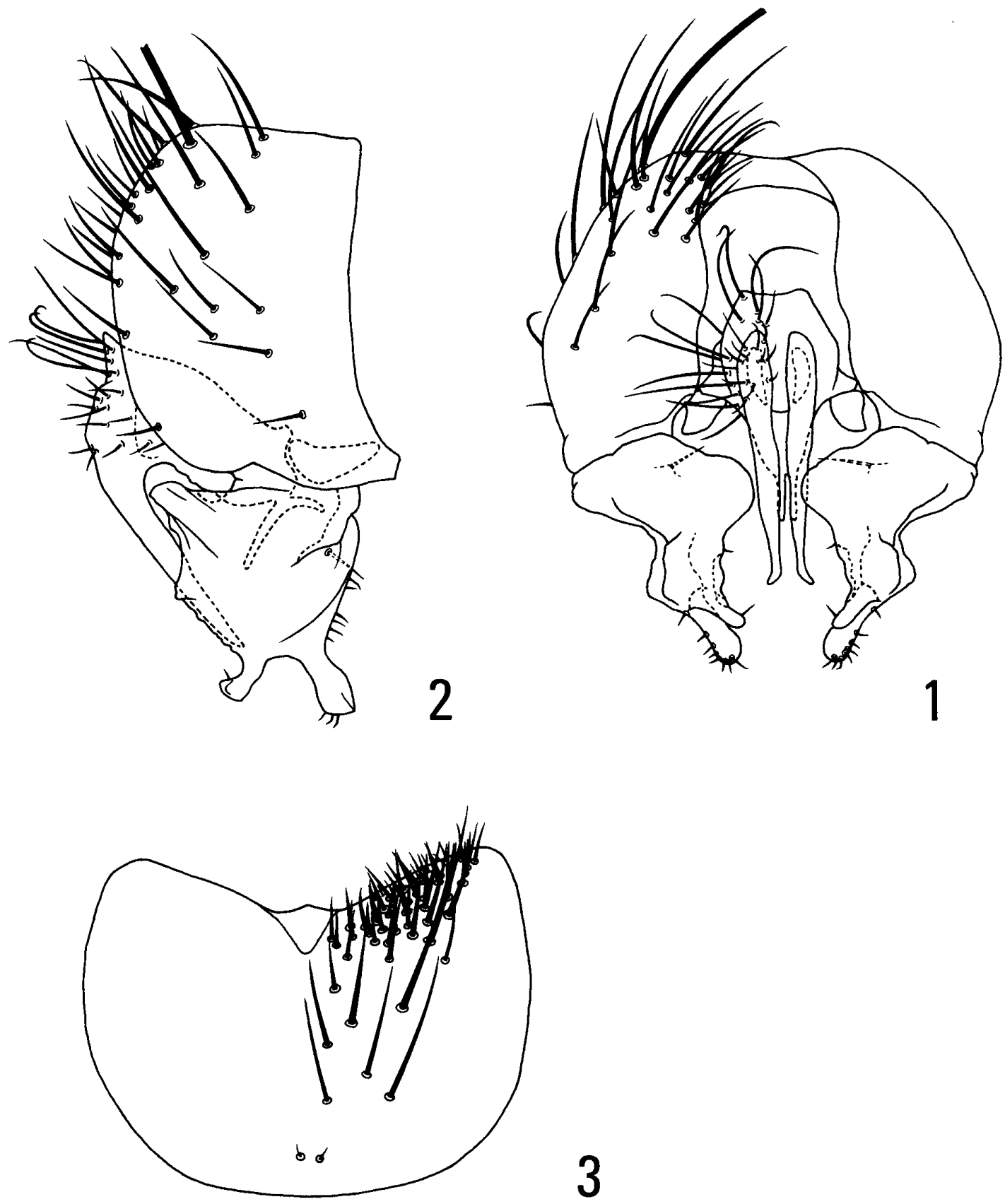

Figs. 1-3. Fannia imperatoria sp. nov., 1, hypopygium, caudo-ventral view; 2, hypopygium, lateral view; 3 , 5th sternite. 
apical margin. Hind femur with a row of long $a$ setae, this row gradually approaching $a d$ surface, below this row with biserial rows of long $a$ setae on basal half, the setae subequal to femoral depth; $a v$ surface with many setulae on basal half, 1/2 times as long as femoral depth, and with a row of 6-8 long strong $a v$ setae on apical half, the setae as long as femoral depth; $v$ surface setulose on basal two-thirds; $p v$ surface with a row of long setae on basal three-quarters, the setae longer than femoral depth, and with a comb-like row of close-set short setulae on apical quarter. Hind tibia with $3 a d$ and $2 a v$ setae.

Abdomen. Ground color black, subshining, but bluish gray pollinose thinly; tergite 5 thinly pollinose, with distinct vitta. With a median black vitta on each tergite, the vitta on tergite 2,3 and 4 slightly broadened apicad, but parallel-sided on tergite 5 .

Hypopygium. Cercal plate with a pair of long sublateral hooks; with a median keel behind the hooks, the keel with two pairs of processes on the bottom, a long pair directed forward and a short pair directed rearward. Bacilliform process of small triangular plate, directed backward. Surstylus strongly sinuate medially in caudo-ventral view; broadened inward; bifurcated apically. Sternite 5 as broad as long, with many short setae along the hind margin and scattered long setae medially. (Figs. 1-3)

Female. Unknown.

Body length. Male: about $5.6 \mathrm{~mm}$.

Type series. Holotype: $\widehat{\sigma}$, Imperial Palace, Tokyo, Japan, 7 April 1999 (S. Shinonaga), in the National Science Museum, Tokyo.

Distribution. Japan (Honshu).

Remarks. Fannia imperatoria sp. nov. seems to belong to the carbonaria group of the carbonaria subgroup with the following characteristics (Chillcott, 1961): hind coxa without hairs on inner $p$ margin, lower squama well developed, abdomen sub-shining, hind femur with 6-8 preapical long $a v$ setae.

$F$. imperatoria is closely allied to $F$. fuscitibia Stein, 1920, although $F$. fuscitibia is distinguishable by the following aspects: upper postoccipital setae absent; frontal setae 7-10; acr triserial; proepimeron with 2 setae; hind femur with 3-5 long av setae on apical half, and $p v$ surface with very short setulae on basal two-thirds; lower squama subequal to upper one; hypopygium quite differs.

Japanese name, "Kinri", means the emperor's garden where people are forbidden to enter.

Fannia urbana sp. nov.

Japanese name: Miyako-hime-iebae

(Figs. 4-8)

Male. Head. Eyes bare, 1.7 times as deep as long. Occipital setae short, regular in length. Upper postoccipital setae uniserial, but sometimes with sparse and incomplete second row. Frontal setae 9-10, sometimes uppermost one reclinate; with some short fine interstitials. 
Frons weakly arched, at narrowest point slightly narrower than width of ocellar triangle. Ground color of parafrontalia, frontal vitta and parafacialia black. Parafrontalia silvery white pollinose, but brownish gray pollinose near ocellar triangle; narrow. Frontal vitta light-brown pollinose; very narrow, but distinct throughout. Parafacialia bare, silvery white pollinose, at lunula slightly narrower than flagellomere. Antennae black; brownish gray subpubescent; flagellomere twice as long as wide. Arista black including basal segment, subpubescent, twice as long as flagellomere. Vibrissal angle behind level of profrons. Proboscis moderate in size, black; prementum moderately sclerotized, thinly pollinose, about 2.5 times as long as wide. Palpi black, as long as proboscis, filiform, little dilated in apical half.

Thorax. Ground color black. Scutum subshining, with brownish gray pollinose thinly, postpronotal area light-gray pollinose thinly. Not vittate. One pra present, long, 1/2 times as long as anterior $n p l$ seta. Prest acr biserial, post acr triserial. Proepisternal depression bare, with 2 setae on ridge beneath. Proepimeron with a strong seta surrounded by several fine long setulae. Scutellum black, brownish gray pollinose; with a pair of strong laterals and apicals, and with a few shorter laterals; discal setulae short and sparse.

Wings. Membrane smoky, but slightly tinged with yellow at base. Veins brown, but paler basad. Squamae pale yellow, with yellow margin and fringe of yellow hairs; lower one well-developed, projecting beyond upper one. Halteres reddish to brownish yellow, stalk darker.

Legs. All legs black, including knees. Fore femur with a row of long $p d$ setae; with pluriserial rows of $p$ setae curled at tips; with a row of $p v$ setae. Fore tibia without $p$ setae, and with no $a d$ at apical quarter. Mid femur with a row of erect short $a$ setae among fine short setulae, but 4-5 preapical a setae stronger and curved backward; with a row of 8-9 wide-spaced $a v$ setae on basal two-thirds, the setae subequal to femoral depth, merging into biserial comb-like rows of close-set short $a v$ setae in apical third, and with a few short $a v$ setulae preapically; with biserial rows of $p v$ setae, the setae of an outer row half as long as femoral depth, the setae of an inner row weaker, followed by biserial rows of short dense $p v$ setae with slightly bent tips, and with a few short preapical $p v$ setulae; $p$ surface with a row of dense long setae, 4 preapical setae stronger. Mid tibia thickened on apical half, twice as deep as basal diameter; with a $v$ mat of setulae on apical half, the setulae $2 / 3$ times as long as tibial depth, and with short sparse semi-decumbent $v$ setulae on basal half; with 2-4 ad and 2-4 pd setae. Mid basal tarsomere without a basal $v$ crest. Hind coxa without any setae on $p$ apical margin. Hind femur of normal shape; $a v$ surface with very short setulae on basal two-thirds, and with a row of 3-4 wide-spaced long $a v$ setae on apical third, the setae about 1.5 times as long as femoral depth; with a row of $a$ setae, the row gradually approaching ad surface, the setae on basal two-thirds weak, but the setae on apical third strong; $v$ surface with sparse short setulae on basal two-thirds; $p v$ surface with short setulae on basal two-thirds, followed by break, and with a row of 4-5 fine preapical setulae. Hind tibia 1-3 av and 3-5 ad setae; with several erect $p$ setulae on apical half. 
Abdomen. About 1.8 times as long as broad. Ground color black; subshining, bluish gray pollinose thinly in posterior view; tergite 5 pollinsoe very thinly, with obscure median vitta. With a narrow black median vitta on each tergite.
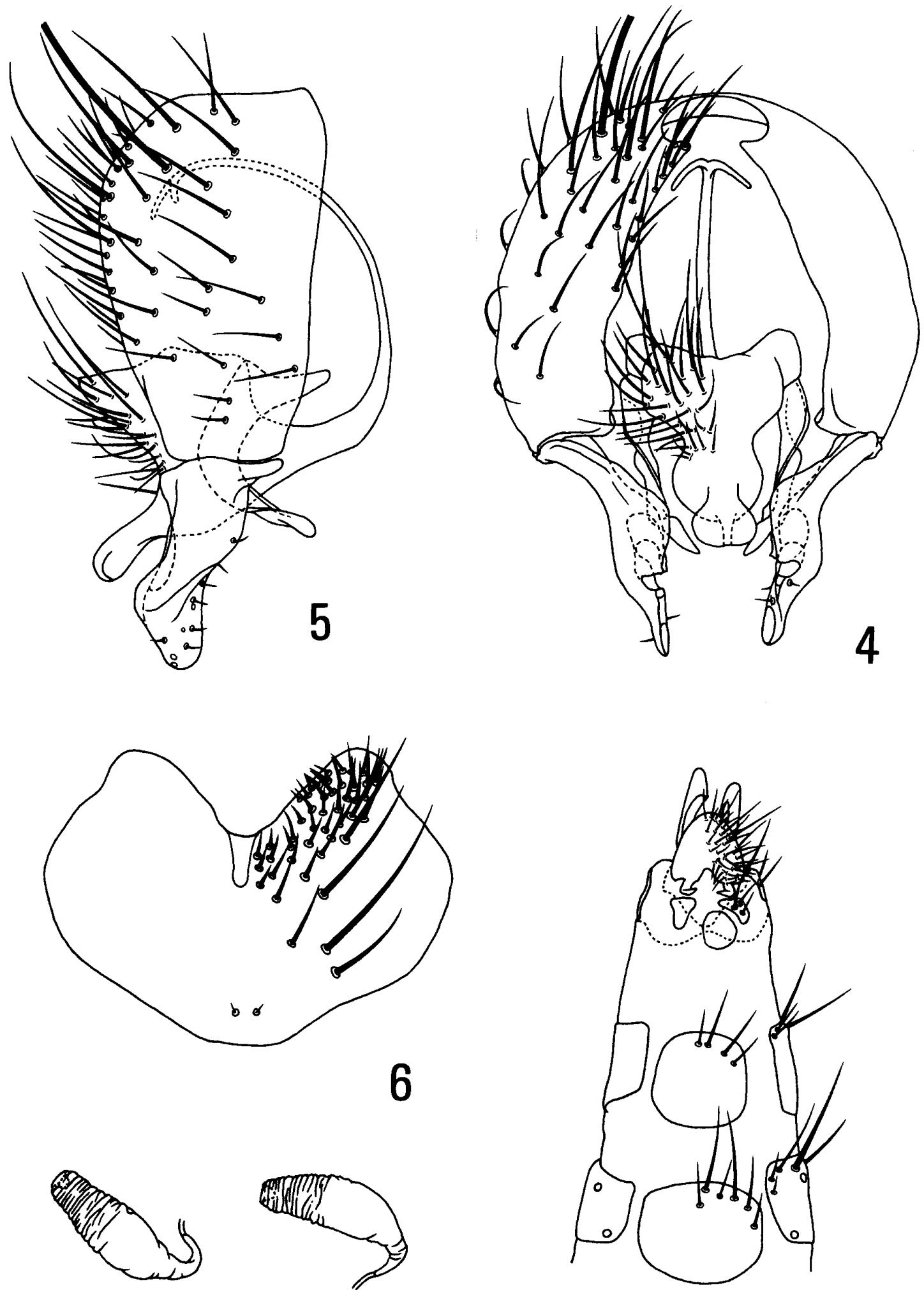

7

8

Figs. 4-8. Fannia urbana sp. nov., 4, hypopygium, caudo-ventral view; 5, hypopygium, lateral view; 6, 5th sternite; 7, spermatheca; 8 , ovipositor, ventral view. 
Vol.53 Suppl.2, 2002

Hypopygium. Cercal plate with a broad basal portion; constricted at base of apical portion, and with an apical button, the tip slightly broadened; apical portion very long, strongly curved inward, with a small forked tip. Surstylus not strongly broadened basally, weakly sinuate, with a small inner excision preapically. Bacilliform process long, slender, weakly bent inward beyond the middle, with basal portion strongly projected backward. Sternite 5 broader than long, strongly indented on hind margin, with numerous short thick setae along the hind margin, and with long setae scattered on the disc. (Figs. 4-6)

Female. Head. Frons at vertex slightly wider than an eye, not arched. Upper postoccipital setae uniserial. Frontal vitta black, at narrowest point $2 / 3$ times as broad as width of a parafrontalia. Parafrontalia black, glossy, but small triangular part along lower eye margin silvery white pollinose, with a convex inner margin. Lower ori seta slightly closer to inner margin of parafrontalia. Frontal setae 5-6, with some short interstitials. Parafrontal setulae in 2 rows below lower ori. Prementum pollinose; swollen, twice as long as wide.

Thorax. Scutum glossier than in male, but very thinly pollinose. One proepimeral seta surrounded by 1-4 fine setulae.

Wings. Wing tip faintly smoky, but yellowish toward base and near costal margin. Veins brownish yellow, paler basad.

Legs. Mid femur with a row of short and close-set $a v$ setae on basal two-thirds, the setae half as long as femoral depth, merging into a row of sub-erect short $a v$ setae in apical third, and with a comb-like row of close-set short preapical setulae; with a row of short $p v$ setae on basal two-thirds, then break and with a comb-like row of some close-set preapical setulae. Mid tibia with $1 a v, 2-3 a d$ and 2-4 pd setae. Hind tibia with 2-4 av and 2-3 ad setae.

Abdomen. Not vittate. Shining black.

Ovipositor. Anterior margin of tergite 6 and 7 indented medially. Tergite 8 strongly reduced medially, almost divided into 2 pieces. Sternite 8 with individual variation in size and shape, weakly sclerotized, reduced to 2-3 small setulose plates with a thin basal sclerotization. Subanal plate slightly longer than broad; with many short setulae on the disc and long setulae along the posterior margin. Spiracle 6 and 7 situated in lateral part of tergite 6 . Two spermathecae present, strongly elongated, corrugated on apical third, slightly swollen pre-medially; the apex with a dimple; duct strongly curved. (Figs. 7 and 8)

Body length. Male: 5.0-5.5mm. Female: $4.2-5.1 \mathrm{~mm}$.

Type series. Holotype: $\delta$, Imperial Palace, Tokyo, Japan, 14 May 2001 (S. Shinonaga). Paratypes: 1ठ, Kami-dokanbori, Imperial Palace, Tokyo, Japan, 24 Apr. 1996 (K. Konishi

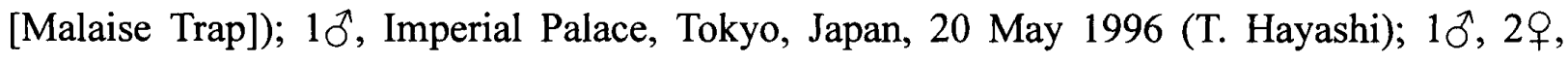
Hukiage Gyoen, Imperial Palace, Tokyo, Japan, 20 May-19 June 1996 (K. Konishi [Malaise Trap]); 2q, Kami-dokanbori, Imperial Palace, Tokyo, Japan, 24 Apr. 1996 (K. Konishi [Malaise Trap]); 1ㅇ, Hukiage-gyoen, Imperial Palace, Tokyo, Japan, 1-22 May 1997 (K. Konishi [Malaise Trap]); 1ㅇ, Imperial Palace, Tokyo, Japan, 18 Apr. 2000 (S. Shinonaga); 10 , 1 , Imperial Palace, Tokyo, Japan, 16 Apr. 2001 (S. Shinonaga); 10, Chiba-University 
Campus, Chiba, Japan, 24 Apr. 1998 (R. Kano). The type-specimens including holotype are deposited in the National Science Museum, Tokyo, except a male paratype is in Reference Museum, Department of Medical Entomology, the National Institute of Infectious Diseases, Tokyo.

Distribution. Japan (Honshu).

Remarks. Fannia urbana sp. nov. belongs to the carbonaria subgroup of the carbonaria group which has following characters (Chillcott, 1961): hind coxa without hairs on inner $p$ margin, well-developed lower squama, subshining abdomen, glossy and wide parafrontalia in female, and the structure of hypopygium supports this.

This new species very closely allied to Fannia corvina (Verrall, 1892) or $F$. vernalis Nishida, 1974. F. corvina differs from this new species in the following aspects: prest acr triserial; genital structure quite differs.

$F$. vernalis differs from this new species in the following characteristics: eyes with dense hairs; about 15 frontal setae present; parafacialia with a row of strong setae; prest acr triserial; hind femur with long $p v$ setae in basal half, and a row of long $a v$ setae on apical half; median vitta of abdomen triangular and wider.

External characteristics of $F$. urbana shows the close relationship with $F$. corvina, although the genital structure indicates the affinity with $F$. vernalis rather than $F$. corvina.

$F$. urbana was collected not only at the Imperial Palace but also the campus of Chiba University, Chiba. This species inhabits in the forest of Kanto Plain widely.

Japanese name "Miyako" means the megalopolis or capital.

\section{ACKNOWLEDGEMENTS}

The author wishes to express his sincere thanks to Dr. S. Shinonaga of Tokyo Medical and Dental University, Tokyo, and Dr. T. Hayashi of National Institute of Infectious Diseases, Tokyo, and the late Dr. R. Kano of Tokyo, for giving him the valuable specimens.

\section{REFERENCES}

Chillcott, J. G. 1961. A revision of the Nearctic species of Fanniinae (Diptera: Muscidae). Can. Ent., 92, Suppl., 14: 1-295.

Nishida, K. 1974. On Eight Species of the Genus Fannia (Diptera: Muscidae) from Japan, with the Description of New Species. Kontyu, 42: 184-191.

Nishida, K. 2000. The Fanniidae (Diptera) of the Imperial Palace, Tokyo. Mem. Natn. Sci. Mus., Tokyo, (36): 457-461.

Rozkosny, R., Gregor, F. and Pont, A. C. 1997. The European Fanniidae (Diptera). Acta Sc. Nat. Borno, 31(2): 1-80, 18 figs. 